\title{
ANALISIS PENGAKUAN PENDAPATAN PERUSAHAAN DARI PEMANFAATAN LIMBAH PRODUKSI DALAM SAK ETAP PADA CV. FRITA ARTA PRIMA DI SURABAYA
}

\author{
*Ade Wahyu, Masyhad, Arief Rahman \\ Program Studi Akuntansi Fakultas Ekonomi dan Bisnis \\ Universitas Bhayangkara Surabaya, Indonesia
}

DOI: $10.46821 /$ equity.v1i1.4

\begin{abstract}
ABSTRAK
Pada perusahaan CV. Frita Arta Prima terdapat banyak sisa-sisa bahan dari proses produksi. Sisa bahan tersebut berupa serbuk kayu halus dan serbuk kayu kasar. Dimana dari sisa bahan ini perusahaan akan mendapatkan sumber pendapatan bagi perusahaan. Pendapatan adalah arus masuk bruto dari manfaat ekonomi yang timbul dari aktivitas normalentitas selama suatu periode ketika arus masuk itu mengakibatkan kenaikan ekuitas, yang tidak berasal dari kontribusi penanaman modal. Dari aktivitas diatas akan muncul suatu masalah tentang bagaimana pengakuan serta pencatatan atas pendapatan tersebut yang sesuai dengan SAK ETAP tahun 2016. Disini penulis memberikan suatu gambaran atau hasil penelitian tentang aktivitas tersebut dimana penjualan dari sisa bahan tersebut masuk kedalam pendapatan lain-lain pada laporan laba rugi perusahaan. Dimana perusahaan telah menjual serbuk kayu Rp. 150.000/ Kg dan telah menjual $540 \mathrm{Kg}$ selama 1 tahun.
\end{abstract}

Kata kunci: Sisa bahan produksi, Pendapatan dari sisa produksi, SAK ETAP.

\begin{abstract}
On the company CV. Frita Arta Prima has many leftovers from the production process. The remaining ingredients are in fine wood powder and coarse wood powder. Where from the rest of this material the company will get a source of income for the company. Income is gross inflows of economic benefits arising from normality activites during a period when the inflows result in an increase in equity, which does not originate from investment contributions. From the above activities a problem will arise regarding how the recognition and recording of these revenues are in accordance with SAK ETAP in 2016. Here the author provides an overview or result of research on these activities where the sale of the the remaining material into other income in the company's income statement. Where the company has sold wood powder Rp. 150.000/ Kg and has sold $480 \mathrm{Kg}$ for one years.
\end{abstract}

Keywords: The rest of the production of materials, Income from the rest of the production, SAK ETAP.

*Corresponding Author:

Email: adewahyuchurnia@gmail.com 


\section{PENDAHULUAN}

Perusahaan adalah suatu organisasi dimana sumber daya (input) seperti bahan baku dan tenaga kerja diproses untuk menghasilkan barang atau jasa (output) bagi pelanggan, yang memanfaatkan berbagai macam sumber-sumber ekonomi yang terbatas untuk dapat memenuhi kebutuhan dengan cara yang menguntungkan. Tujuan utama dari perusahaan baik yang berskala besar maupun kecil adalah agar dapat mempertahankan kelangsungan hidup perusahaan, berkembang dam memperoleh laba maksimal.

Ada beberapa metode pengakuan pendapatan yang diterapkan dalam perusahaan yaitu accrual basis dan cash basis. Metode accrual basis yaitu pendapatan diakui pada saat terjadinya transaksi tanpa menghiraukan kas yang diterima atau dibayarkan. Sedangkan metode cash basis yaitu mengakui pendapatan pada saat kas diterima (Hermawan dan Masyhad, 2006).

Pendapatan adalah arus masukbruto dari manfaat ekonomi yang timbul dari aktivitas normalentitas selama suatu periode ketika arus masuk itu mengakibatkan kenaikan ekuitas, yang tidak berasal dari kontribusi penanaman modal (SAK ETAP, 2016).

Untuk mengatasi permasalahan tersebut, maka disusunlah Dewan Standar Akuntansi Keuangan Ikatan Akuntan Indonesia (DSAK IAI) menyusun Standar Akuntansi Keuangan Entitas Tanpa Akuntabilitas Publik (SAK ETAP) yang diperuntukkan bagi Entitas Tanpa Akuntabilitas Publik (ETAP) yang disahkan pada tanggal 19 Mei 2009 dan baru diberlakukan pada 1 Januari 2011, dan penerapan dini diperkenankan (SAK ETAP, 2016).

ETAP adalah entitas yang tidak memiliki akuntabilitas publik signifikan dan menerbitkan laporan keuangan untuk tujuan umum (general purpose financial statement) bagi pengguna eksternal (SAK ETAP, 2016).

Pada praktik akuntansi CV. Frita Arta Prima dalam penerapan pengakuan pendapatannya belum sepenuhnya sesuai dengan SAK ETAP. Dalam pengakuan pendapatan yaitu pada akhir tahun dalam laporan keuangan CV. Frita Arta Prima tidak mencatat pendapatan hasil penjualan serbuk kayu untuk surat jalan yang belum terbayarkan, yaitu bulan noveber dan desember. Sehingga laporan akhir tahun CV. Frita Arta Prima tidak menunjukkan hasil yang sebenarnya sehingga perlu disesuaikan dengan SAK ETAP.

\section{LANDASAN TEORI}

\section{Pengertian Pendapatan}

Menurut SAK ETAP (IAI, 2016:121): "Pendapatan adalah arus masuk bruto dari manfaat ekonomi yang timbul dari aktivitas normalentitas selama suatu periode ketika arus masuk itu mengakibatkan kenaikan ekuitas, yang tidak berasal dari kontribusi penanaman modal". 
Pengertian Pengakuan Pendapatan

Vol. 1 No. 12020

Menurut (Suwardjono, 2014:362) :"Pengakuan (Recognition) adalah pencatatan jumlah rupiah secara resmi ke dalam sistem akuntansi sehingga jumlah tersebut terrefleksi dalam statemen keuangan".

\section{Pengakuan Pendapatan Dari Limbah Produksi}

Menurut (Mulyadi, 2015:298) dikatakan bahwa jika di dalam proses produksi terdapat sisa bahan, masalah yang timbul adalah "bagaimana memperlakukan hasil penjualan sisa bahan tersebut. Hasil penjualan sisa bahan dapat diperlakukan sebagai":

1. Pengurang biaya bahan baku yang dipakai dalam pesanan yang menghasilkan sisa bahan tersebut.

2. Pengurang terhadap biaya overhead pabrik yang sesungguhnya terjadi.

3. Penghasilan di luar usaha (other income).

\section{Pengertian SAK ETAP}

Standar Akuntansi Keuangan Entitas Tanpa Akuntabilitas Publik (SAK ETAP) adalah standar yang dibuat dengan maksud untuk digunakan oleh entitas tanpa akuntabilitas publik. Entitas tanpa akuntabilitas publik adalah entitas yang:

a. Tidak memiliki akuntabilitas publik signifikan; dan

b. Menerbitkan laporan keuangan untuk tujuan umum (general purpose financial statement) bagi pengguna eksternal. Contoh pengguna eksternal adalah pemilik yang tidak terlibat langsung dalam pengelolaan usaha, kreditur, dan lembaga pemeringkat kredit.

Entitas memiliki akuntabilitas publik signifikan jika:

a. Entitas telah mengajukan pernyataan pendaftaran, atau dalam proses pengajuan pernyataan pendaftaran, pada otoritas pasar modal atau regulator lain untuk tujuan penerbitan efek di pasar modal; atau

b. Entitas menguasai aset dalam kapasitas sebagai fidusia untuk sekelompok besar masyarakat, seperti bank, entitas asuransi, pialang dan atau pedagang efek, dana pensiun, reksa dana dan bank investasi.

\section{METODE PENELITIAN}

\section{Objek Penelitian}

Objek penelitian ini adalah CV. Frita Arta Prima di Surabaya, di Wisma Lidah Kulon A 118 Surabaya. Dimana penelitian ini membahas tentang pengakuan pendapatan.

\section{Pendekatan Penelitian}

Pendekatan penelitian yang digunakan penulis adalah pendekatan kualitatif. Metode penelitian kualitatif adalah penelitian yang digunakan untuk menyelidiki, menemukan, menggambarkan, dan menjelaskan kualitas atau keistimewaan dari 
pengaruh sosial yang tidak dapat dijelaskan, diukur atau digambarkan melalui pendekatan kuantitatif (Sugiyono, 2009:15).

\section{Jenis dan Sumber Data}

\section{Jenis Data}

Jenis data yang digunakan penulis adalah penelitian kualitatif. Data kualitatif adalah data yang diperoleh dalam bentuk informasi dari instansi maupun pihakpihak lain yang ada kaitannya dengan masalah yang akan dibahas.

\section{Sumber Data}

Adapun sumber data yang digunakan yaitu:

\section{Data primer}

Data yang diperoleh dari responden melalui kuesioner, kelompok fokus, panel, atau juga data hasil wawancara peneliti dengan narasumber (Sugiyono,2009). Penulis melakukan pengamatan langsung terhadap obyek yang diteliti yaitu pada CV. Frita Arta Prima yang berisi : Struktur Organisasi, Surat Jalan, Laporan Laba Rugi.

\section{Data sekunder}

Data yang didapat dari catatan, buku, majalah berupa laporan keuangan publikasi perusahaan, laporan pemerintah, artikel, buku-buku sebagai teori, majalah dan lain sebagainya. Seperti SAK ETAP, buku-buku yang dapat melengkapi teori-teori yang diperlukan dalam penulisan ini (Sugiyono,2009).

\section{Teknik Pengumpulan Data}

Metode pengumpulan data yang dilakukan peneliti adalah dengan cara :

a. Observasi adalah teknik pengumpulan data melalui pengamatan. Dengan melakukan observasi langsung terhadap CV. Frita Arta Prima peneliti dapat mengamati obyek penelitian dengan lebih cermat dan detail, misalnya peneliti dapat mengamati kegiatan obyek yang diteliti.

b. Wawancara bertujuan untuk saling menyelami pandangan/pikiran tentang sesuatu yang menjadi obyek penelitian. Seperti melakukan tanya jawab langsung terhadap pihak-pihak yang berwenang dalam perusahaan.

c. Kepustakaan, yaitu mengumpulkan sejumlah informasi mengenai teori-teori yang berhubungan dengan pendapatan, SAK ETAP, dan teori lainnya yang mendukung obyek penelitian.

\section{HASIL DAN PEMBAHASAN}

\section{Hasil Analisis}

Hasil analisis yang dapat peneliti peroleh bahwa CV. Frita Arta Prima mengakui pendapatan dari hasil pemanfaatan limbah produksi dengan menggunakan metode accrual basis. CV. Frita Arta Prima mencatat transaksi tersebut ke dalam akun pendapatan lain-lain bukan kedalam akun pendapatan. Dengan melihat proses dan 
perjanjian penjualan maka untuk jumlah pendapatan yang dapat diterima oleh perusahaan yang berasal dari limbah produksi yaitu dari penjualan bulan januari oktober yang telah dibayar dan terkumpul sebanyak $480 \mathrm{Kg}$. Jadi perusahaan mencatat pendapatan lain-lain sebesar $480 \mathrm{Kg}$ x $150.000=\mathrm{Rp} .72 .000 .000$.

Dari hasil perhitungan diatas dapat kita ketahui bahwa perusahaan akan mencatat bahwa perusahaan telah memperoleh pendapatan lain-lain dari pemanfaatan limbah Produksi sebesar Rp. 72.000.000 yang telah terbayarkan.

\section{Perbandingan Laporan Laba Rugi Perusahaan dan Hasil Analisis}

Hasil analisis yang didapat oleh peneliti adalah bahwa pendapatan lain-lain pada laporan laba rugi CV. Frita Arta Prima yang jumlah awalnya Rp. 72.000.000 menjadi Rp. 81.000.000. Selisih tersebut diperoleh dari penjualan selama 1 tahun yaitu bulan januari - bulan oktober. Serbuk kayu halus dan kasar diberi harga Rp. 150.000 / Kg oleh perusahaan CV. Frita Arta Prima. Perusahaan telah melakukan penjualan serbuk kayu sebanyak 480kg dan pembeli telah melakukan pembayaran sebesar Rp. 72.000.000 selama 10 bulan (bulan Januari - bulan Oktober). Sedangkan untuk 2 bulan terakhir (bulan november - bulan desember) perusahaan telah melakukan penjualan sebesar $60 \mathrm{~kg}$ dan pembeli belum membayar sebesar Rp. 9.000 .000 dan perusahaan memiliki tagihan kepada pembeli sebesar Rp. 9.000.000. Maka dari itu terdapat perbandingan laporan laba rugi perusahaan dengan laporan laba rugi hasil analisis (Lampiran 1).

\section{Perbandingan Neraca Perusahaan dan Neraca Hasil Analisis}

Untuk neraca hasil analisis yang peneliti peroleh yaitu jumlah yang belum terbayar masuk kedalam neraca sebesar Rp. 9.000.000 pada akun piutang usaha. Yang awalnya perusahaan tidak mencatatnya kedalam neraca dan memiliki perbedaan setelah jumlah penjualan yang belum terbayarkan masuk kedalam neraca (Lampiran 2).

\section{Perbandingan Laporan Modal Kerja Perusahaan Dan Laporan Modal Kerja Hasil Analisis}

Untuk laporan modal kerja hasil analisis juga memiliki perbedaan dengan laporan modal kerja perusahaan sebesar Rp. 1.006.443.112 menjadi Rp. 1.015.443.112 (Lampiran 3).

\section{Interpretasi}

Jumlah pendapatan lain-lain yang diterima oleh perusahaan adalah sebesar Rp. 72.000.000. Dari pencatatan jumlah pendapatan lain-lain tersebut maka akun yang muncul adalah akun pendapatan lai-lain sebesar Rp. 72.000.000 diperoleh dari terjadinya pembayaran $480 \mathrm{Kg}$ selama 10 Bulan.

Apabila perusahaan menggunakan rumus yang sesuai dengan SAK ETAP (Standar Akuntansi Keuangan Entitas Tanpa Akuntabilitas Publik) untuk menghitung akun pendapatan diluar usaha akan menunjukan nilai nominal sebesar 
Rp. 81.000.000 walaupun ada surat jalan yang belum terbayarkan. Jika perusahaan menggunakan rumusan ini maka dalam laporan keuangan perusahaan akan muncul sebanyak akun yang berhubungan dengan transaksi tersebut. akunakun yang akan timbul adalah akun pendapatan diluar usaha sebesar Rp. 81.000.000, akun kas sebesar Rp. 72.000.000, dan piutang usaha sebesar Rp. 9.000.000 jika ada $60 \mathrm{Kg}$ serbuk kayu yang belum terbayarkan.

\section{SIMPULAN}

Berdasarkan hasil dari kesimpulan yang telah diutarakan dalam Bab IV, maka peneliti dapat mengambil kesimpulan bahwa pengakuan pendapatan yang dilakukan oleh CV. Frita Arta Prima belum sesuai dengan SAK ETAP karena pada saat pencatatan pendapatan dari pemanfaatan limbah tersebut pihak keuangan tidak mencatatat surat jalan yang belum terbayarkan. Tetapi hanya mencatat surat jalan yang telah terbayarkan. Akibat yang ditimbulkan dari pencatatan yang dilakukan oleh perusahaan adalah berkurangnya nilai akun pendapatan diluar usaha perusahaan sebesar Rp. 9.000.000. Karena belum adanya proses pembayaran dari pihak pembeli, sehingga dalam akun piutang dan pendapatan diluar usaha terjadi selisih Rp. 9.000.000 dengan pencatatan yang sesuai dengan SAK ETAP dan teori-teori lainnya. Saran yang dapat peneliti sampaikan dalam kesempatan kali ini untuk pihak perusahaan adalah sebaiknya pihak perusahaan mencatatat sesuai dengan peraturan yang tertera dalam SAK ETAP yaitu mengeluarkan bagian yang telah menjadi hak dari pihak ketiga agar pelaporan yang disajikan sesuai dengan nilai nominal yang di dapat oleh perusahaan atau nilai yang sebenarnya. Jika perusahaan mencatatat penerimaan tersebut sesuai dengan peraturan yang tertera dalam SAK ETAP dapat dipastikan bahwa pimpinan perusahaan akan dapat melihat seberapa besar kontribusi yang diberikan dari limbah produksi tersebut dengan sebenar-benarnya atau sesuai dengan pendapatan yang benar- benar didapat oleh perusahaan.

\section{DAFTAR PUSTAKA}

IAI, ETAP 2016, Standar Akuntansi Keuangan Entitas Tanpa Akuntabilitas Publik, Cetakan Kelima, Dewan Standar Akuntansi Keuangan Ikatan Akuntan Indonesia, Jakarta.

Suwardjono 2014, Teori Akuntansi, Anggota IKAPI, Yogyakarta. 
Lampiran 1. Laporan Laba Rugi Perusahaan dengan Laporan Laba Rugi Hasil Analisis

\begin{tabular}{|c|c|c|c|}
\hline \multicolumn{2}{|c|}{$\begin{array}{l}\text { CV. Frita Arta Prima } \\
\text { Laporan Laba Rugi } \\
\text { Desember } 2018\end{array}$} & \multicolumn{2}{|c|}{$\begin{array}{c}\text { CV. Frita Arta Prima } \\
\text { Laporan Laba Rugi Hasil Analisa } \\
\text { Desember } 2018\end{array}$} \\
\hline PENDAPATAN & Rp. 3.767.877.888 & PENDAPATAN & Rp. 3.767.877.88 \\
\hline \multirow[t]{2}{*}{ Pendapatan lain-lain } & Rp. 72.000.000 & \multirow[t]{2}{*}{ Pendapatan lain-lain } & Rp. 81.000.000 \\
\hline & Rp. 3.839.877.888 & & Rp. 3.848.877.888 \\
\hline HPP : & & HPP : & \\
\hline Persediaan (Awal) & - & Persediaan (Awal) & - \\
\hline Pembelian FP & Rp. 2.519.003.349 & Pembelian FP & Rp. 2.519.003.349 \\
\hline \multirow[t]{2}{*}{ Pembelian Tunai } & Rp. 370.000 .000 & \multirow[t]{2}{*}{ Pembelian Tunai } & Rp. 370.000 .000 \\
\hline & Rp. 2.889.003.349 & & Rp. 2.889.003.349 \\
\hline Persediaan Akhir & $\begin{array}{c}- \\
\text { Rp. } 2.889 .003 .349\end{array}$ & Persediaan Akhir & $\begin{array}{c}- \\
\text { Rp. } 2.889 .003 .349\end{array}$ \\
\hline Upah & Rp. 196.200 .000 & Upah & Rp. 196.200 .000 \\
\hline \multirow[t]{2}{*}{ Biaya Proyek } & Rp. 138.260 .600 & \multirow[t]{2}{*}{ Biaya Proyek } & Rp. 138.260 .600 \\
\hline & Rp. 3.223.463.949 & & Rp. 3.223.463.949 \\
\hline LABA KOTOR & Rp. 616.413 .939 & LABA KOTOR & Rp. 625.413.939 \\
\hline BIAYA & & BIAYA & \\
\hline OPERASIONAL: & & OPERASIONAL: & \\
\hline Gaji & Rp. 62.000 .000 & Gaji & Rp. 62.000 .000 \\
\hline Penyusutan & Rp. 5.805.673 & Penyusutan & Rp. 5.805.673 \\
\hline Biaya Telephone & Rp. 6.764.191 & Biaya Telephone & Rp. 6.764.191 \\
\hline Biaya Listrik & Rp. 10.137.166 & Biaya Listrik & Rp. 10.137.166 \\
\hline Biaya Transport & Rp. 8.955.000 & Biaya Transport & Rp. 8.955.000 \\
\hline Biaya ATK & Rp. 2.274.000 & Biaya ATK & Rp. 2.274.000 \\
\hline Biaya Perawatan & Rp. 12.500 .000 & Biaya Perawatan & Rp. 12.500 .000 \\
\hline \multirow[t]{2}{*}{ Biaya Supplay } & Rp. 25.000.000 & \multirow[t]{2}{*}{ Biaya Supplay } & Rp. 25.000 .000 \\
\hline & Rp. 133.436 .030 & & Rp. 133.436 .030 \\
\hline BERSIH & Rp. 482.977 .909 & BERSIH & Rp. 491.977.909 \\
\hline \multicolumn{2}{|l|}{ SEBELUM PAJAK } & \multicolumn{2}{|l|}{ SEBELUM PAJAK } \\
\hline \multicolumn{2}{|l|}{ PENGHASILAN } & \multicolumn{2}{|l|}{ PENGHASILAN } \\
\hline JUMLAH PAJAK & & JUMLAH & \\
\hline \multicolumn{2}{|l|}{ PENGHASILAN: } & \multicolumn{2}{|l|}{ PENGHASILAN: } \\
\hline PPH FINAL & Rp. 65.922.049 & PPH FINAL & Rp. 65.922.049 \\
\hline \multirow[t]{2}{*}{ PPH PS. 29} & Rp. 2.213 .126 & \multirow[t]{2}{*}{ PPH PS. 29} & Rp. 2.213.126 \\
\hline & Rp. 68.135.175 & & Rp. 68.135.175 \\
\hline BERSIH & Rp. 414.842 .734 & BERSIH & Rp. 423.842.734 \\
\hline SETELAH PAJAK & & SETELAH & \\
\hline PENGHASILAN & & PENGHASILAN & \\
\hline
\end{tabular}

Sumber: Data Olahan Peneliti (2019) 
Ade Wahyu dkk., Analisis Pengakuan Pendapatan

Lampiran 2. Perbandingan Neraca Perusahaan dan Neraca Hasil Analisis

\begin{tabular}{|c|c|}
\hline $\begin{array}{c}\text { CV. Frita Arta Prima } \\
\text { Neraca } \\
\text { Per } 31 \text { Desember } 2018 \\
\end{array}$ & $\begin{array}{l}\text { CV. Frita Arta Prima } \\
\text { Neraca Hasil Analisis } \\
\text { Per } 31 \text { Desember } 2018 \\
\end{array}$ \\
\hline AKTIVA LANCAR: & AKTIVA LANCAR: \\
\hline 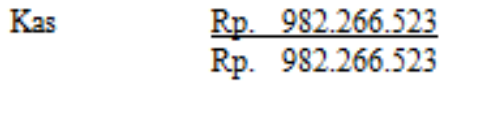 & $\begin{array}{llc}\text { Kas } & \text { Rp. } & 982.266 .523 \\
\text { Piutang } & \text { Rp. } & \mathbf{9 . 0 0 0 . 0 0 0}\end{array}$ \\
\hline AKTIVA TETAP : & Rp. $\quad 991.266 .523$ \\
\hline Nilai Perolehan Rp. $\quad 64.250 .000$ & AKTIVA TETAP : \\
\hline $\begin{array}{lll}\text { Akml. Peny. } & \text { Rp. } & 37.860 .285 \\
\text { Nilai Bulvy } & 26.389715\end{array}$ & Nilai Perolehan Rp. $\quad 64.250 .000$ \\
\hline 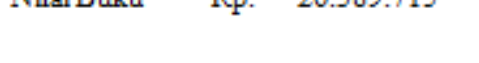 & Akml. Peny. $\quad$ Rp. $\quad 37.860 .285$ \\
\hline JUMLAH $\quad \underline{\text { Rp.1.008.656.238 }}$ & Nilai Buku $\quad$ Rp. $\quad 26.389 .715$ \\
\hline $\begin{array}{l}\text { KEWAJIBAN LANCAR: } \\
\text { Hutang PPH PS.29Rp. } \quad 2.213 .126\end{array}$ & JUMLAH $\underline{\underline{\text { Rp. } .017 .656 .238}}$ \\
\hline $\begin{array}{l}\text { MODAL: } \\
\text { Modal usaha } \quad \text { Rp. } 1.006 .443 .112\end{array}$ & $\begin{array}{l}\text { KEWAJIBANLANCAR: } \\
\text { Hutang PPH PS.29Rp. } \quad 2.213 .126 \\
\text { MODAL: }\end{array}$ \\
\hline $\begin{array}{l}\text { Jumlah Kewajiban Rp.1.008.656.238 } \\
\text { Dan Modal }\end{array}$ & Modalusaha Rp. 1.015.443.112 \\
\hline & $\begin{array}{l}\text { Jumlah Kewajiban } \underline{\underline{R} .1 .017 .656 .238} \\
\text { Dan Modal }\end{array}$ \\
\hline
\end{tabular}

Sumber : Diolah Peneliti (2019)

Lampiran 3. Laporan Modal Kerja Hasil Analisis

\begin{tabular}{|c|c|c|c|}
\hline \multicolumn{2}{|c|}{$\begin{array}{l}\text { CV. Frita Arta Prima } \\
\text { Laporan Modal Kerja } \\
\text { Tahun } 2018 \\
\end{array}$} & \multicolumn{2}{|c|}{$\begin{array}{c}\text { CV. Frita Arta Prima } \\
\text { Laporan Modal Kerja Hasil Analisis } \\
\text { Tahun } 2018\end{array}$} \\
\hline $\begin{array}{l}\text { MODAL } \\
\text { LABA Tahun Berjalan }\end{array}$ & $\begin{array}{c}\text { Rp. } \quad 691.600 .378 \\
\text { Rp. } \quad 414.842 .734 \\
\text { Rp. } 1.106 .443 .112\end{array}$ & $\begin{array}{l}\text { MODAL } \\
\text { LABA Tahun Berjalan }\end{array}$ & $\begin{array}{ll}\text { Rp. } \quad 691.600 .378 \\
\text { Rp. } \quad \mathbf{4 2 3 . 8 4 2 . 7 3 4} \\
\text { Rp. 1.115.443.112 }\end{array}$ \\
\hline PRIVE & $\underline{\text { Rp. } \quad 100.000 .000}$ & PRIVE & Rp. 100.000 .000 \\
\hline \multicolumn{2}{|c|}{ MODAL USAHA AKHIRRp.1.006.443.1.12 } & \multicolumn{2}{|c|}{ MODAL USAHA AKHIR Rn, $1,016,443,112$} \\
\hline
\end{tabular}

